\title{
ESPECIAL VENTURE CAPITAL
}

\section{Indústria de empreendimentos}

A indústria de private equity e venture capital desempenha um papel de grande importância no financiamento de empreendedores e inovações no Brasil, podendo ser considerada responsável pelo rápido desenvolvimento de setores como Internet, tecnologia de informação e biotecnologia. 0 artigo descreve as características e história dessa indústria no país, as etapas envolvidas no processo de investimento e as dificuldades e tendências dessa indústria nos próximos anos.

por Ricardo Ratner Rochman FGV-EAESP

O que empresas como FedEx, Apple, Intel, ALL Logística, Dasa, Totvs e Alellyx têm em comum? Todas receberam recursos financeiros $e$ gerenciais, em alguma fase do seu desenvolvimento, de empresas gestoras de private equity ou venture capital (PE/VC). A indústria de PE/VC vem crescendo a passos largos nos últimos anos.

Para se ter uma idéia, somente em 2006 foram captados mundialmente mais de US\$ 432 bilhões, e as expectativas é de que 2007 seja um ano ainda mais promissor, com um crescimento esperado de $16 \%$ em relação ao ano anterior, conforme dados da Private Equity Intelligence Ltd., que englobam as operações realizadas com aquisições (buyouts), venture capital (capital de risco), infra-estrutura, setor imobiliário e outros fundos de investimentos.

0 primeiro censo brasileiro da 
indústria de private equity e venture capital aponta a presença, no país, de 71 organizações gestoras de investimento de PENC que, agregadamente, comprometeram mais de US $\$ 5,58$ bilhões no Brasil em 2004, deforma tradicional ou por meio de PIPE (Privatelnvestment in Public Equity), como podemos constatar no gráfico a seguir.

O que é PENC. Private equity éum termo empregado de maneira ampla para designar 0 investimento em empresas e ativos cujas ações ou cotas não sejam negociadas publicamente em um mercado organizado, como, por exemplo, o de Bolsa de Valores.
Já o termo venture capital, conhecido também como capital de risco, diz respeito aos investimentos de private equity realizados em empresas que sejam novas, ou estejam em fase inicial de desenvolvimento, eque geralmente representam um alto risco para os seus empreendedores e investidores.

Costuma-se designar o capital investido pela indústria de PE/VC de capital empreendedor, pois ele almeja o desenvolvimento e crescimento dos negócios investidos, que são chamados normalmente de empresas investidas. Temos então na indústria de PE/VC os seguintes participantes: os investidores, que são as pessoas ou empresas que fornecem recursos para serem investidos em al gum negócio, esperando, em troca, uma determinada taxa de retorno para um horizonte definido; as empresas gestoras de PE/NC, que captam e gerenciam os recursos dos investidores, decidindo onde investir e por quanto tempo, auxiliando o empreendedor ou empresa investida a atingir suas metas; e os empreendedores ou empresas investidas, que recebem os recursos das empresas gestoras para investir nos seus projetos com objetivo de prover a taxa de retorno esperada pelos investidores.

Os investidores de PE/VC possuem horizonte de investimento que

\section{EVOLUÇÃO DO CAPITAL COMPROMETIDO}

Saldo de Capital Comprometido ao final de cada ano segundo tipo de investimento (PE/VC tradicional ou PIPE). Foi contabilizado 0 valor integral dos veículos pan-americanos que não têm limites preestabelecidos de alocação dos recursos para o Brasil. Não inclui comprometimentos de ABN Amro Capital, Innovate eVentureLabs. Os comprometimentos da Intel Capital foram estimados com base em informações públicas, assumindo 0 aporte médio de US\$ 1 milhão por empresa investida.

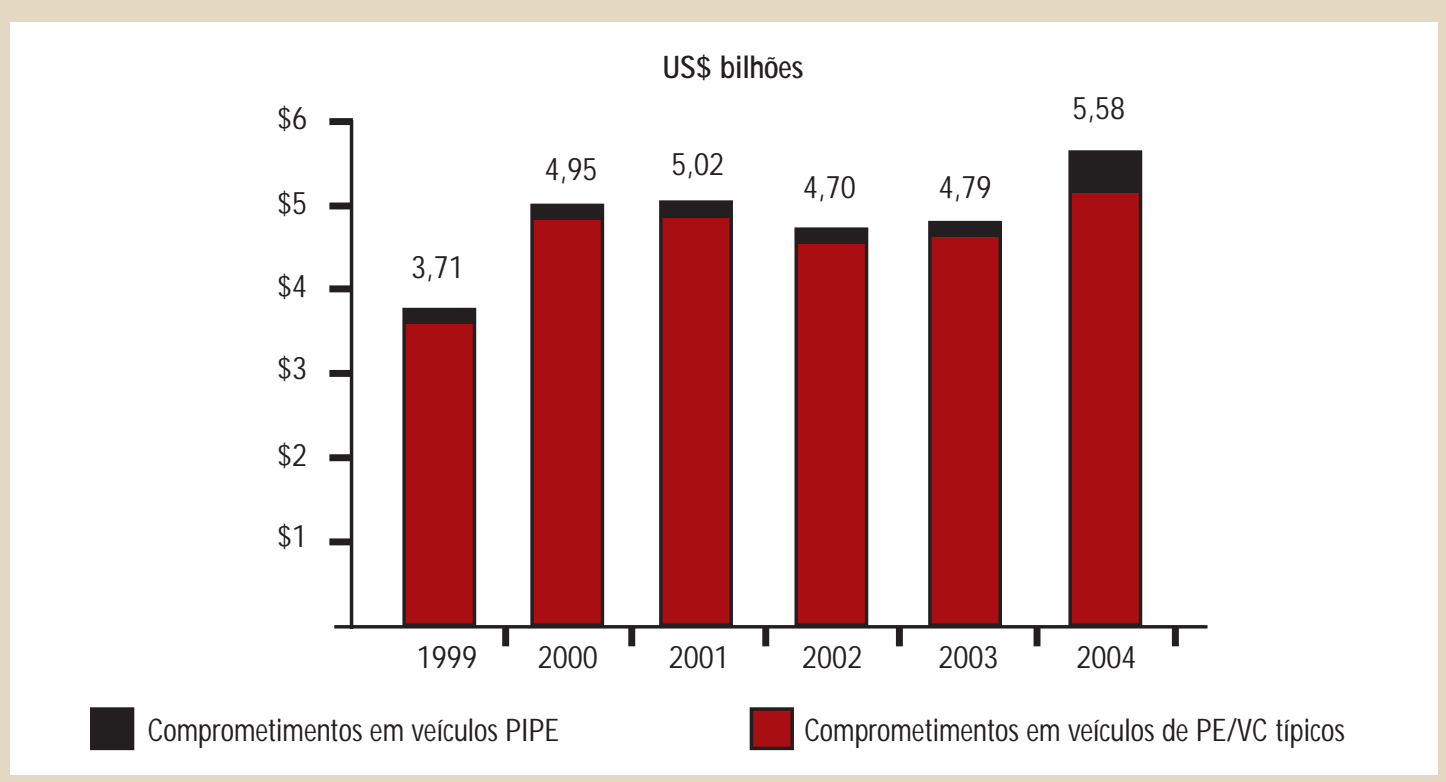

Copyright @ 2005 Censo Brasileiro de PE/VC. Todos os direitos reservados.

Gráfico - Evolução do capital comprometido.

Fonte: Primeiro Censo Brasileiro de Private Equity eVenture Capital. 
varia usualmente de 3 a 7 anos. Uma vez vencido esse prazo, o capital investido e seu retorno, se houver, são retirados, seja por meio da venda da sua participação na empresa, ou venda das ações, ou até mesmo pela assunção do prejuízo no caso do fracasso do empreendimento.

História da indústria. Apesar de os investimentos em PENC possuírem uma origem muito distante, considera-se o General Georges Doriot como o pai da moderna indústria de venture capital, com a fundação da American Research and Development Corporation, em 1946.

Em 1958, foi promulgado nos Estados Unidos o Small Business Investment Act, o qual autorizou a criação das companhias de investimentos direcionadas para pequenas empresas. Na seqüência, em 1982, foi promulgado o Bay-Dole Act, que instituiu a obrigação de que as agências federais responsáveis por atividades inovadoras dedicassem parte de seus orçamentosà subvenção das atividades deinovação e pesquisa e desenvolvimento, realizadas por instituições científicas, e à transferência de tecnologia para empresas de base tecnológica.

Depois desses atos, a indústria de PE/VC estruturou-se setorialmente e passou a receber grandes aportes decapital, sobretudo provenientes dos fundos de pensão com carteiras bilionárias e longos horizontes de investimentos. Desses programas e investimentos surgiram gigantes como a FedEx, Genentech e Intel, por exemplo.

No Brasil, os investimentos em PE/ VC receberam um impulso importante

0 apoio contínuo na gestão da empresa é um fator que diferencia os investimentos PE/VC dos tradicionais, seja ele por meio da criação de uma estrutura de governança corporativa ou até de contatos para trocas de tecnologia com empresas do mesmo setor localizadas no exterior.

com a constituição da BNDES Participações (BNDESPAR), em 1982, criada para possibilitar a subscrição devalores mobiliários no mercado de capitais brasileiro. Em 1991, a BNDESPAR criou o Programa CONTEC, voltado para o financiamento de pequenas e médias empresas de base tecnológica.

A Comissão de Valores Mobiliários (CVM) também teve colaboração importante no desenvolvimento da indústria de PE/VC no país, notadamente com a promulgação da instrução 209, em 1994. Essa instrução permitiu a constituição de Fundos Mútuos de Investimento em Empresas Emergentes (FIEE), as quais podem receber recursos financeiros de investidores institucionais, como de fundos de pensão. Tais fundos, como se observa na tabela a seguir, foram responsáveis por $22,4 \%$ dos investimentos comprometidos em 2004 em PE/VC.

Em 2003 foi promulgada a instrução 391, que permitiu a formação dos fundos de investimento em participações (FIP). Tanto os FIEE como os FIP, juntamente com os fundos de investimentos imobiliários (FII), podem ser considerados veículos de investimentos em private equity e/ou venture capital, somando-se às outras fontes tradicionais de investimento, tais como empresas limitadas, sociedades por ações e holdings.

Além dos esforços da BNDESPAR e da CVM, podemos destacar ainda o papel da Financiadora de Estudos e Projetos (Finep), criada em 1967. A Finep é uma empresa pública vinculada ao Ministério da Ciência e Tecnologia e tem como missão promover e financiar a inovação e a pesquisa científica e tecnológica em empresas, universidades, institutos tecnológicos, centros de pesquisa e outras instituições públicas ou privadas brasileiras.

No entanto, a Finep financia apenas as etapas anteriores à produção, não apoiando investimentos para expansão da produção. A lacuna é preenchida pela Associação Brasileira de Private Equity e Venture Capital (ABVCAP), que tem a missão de ampliar e aprimorar as várias frentes de investimento de longo prazo no Brasil, em sintonia com as principais práticas internacionais nesse tema, quando aplicáveis às condições e ao mercado brasileiro.

As fases do investimento. 0 setor de PE/VC tem propiciado às empresas e empreendedores uma 
fonte adicional de recursos de médio e longo prazo para realizar seus investimentos. Eleconcorrecom outras fontes tradicionais, tais como os empréstimos e financiamentos das instituições financeiras ou a emissão de ações ou debêntures no mercado de capitais.

Além dos recursos financeiros, 0 apoio contínuo na gestão da empresa é um fator que diferencia os investimentos PE/VC dos tradicionais, seja ele por meio da criação de uma estrutura de governança corporativa ou até de contatos para trocas de tecnologia com empresas do mesmo setor localizadas no exterior.

0 processo de investimento em $\mathrm{PE} / \mathrm{VC}$ inicia-se com a empresa gestora captando recursos financeiros com investidores que possuem horizonte de médio ou longo prazo e que pretendem alocar parte dos seus ativos em projetos de alto risco. No Brasil, aproximadamente $83 \%$ das empresas gestoras levaram até 20 meses para captar os recursos necessários para os projetos pretendidos.

As empresas gestoras normalmente focam em determinados projetos, como biotecnologia ou sistemas de informação, ou em algum tipo de investimento, tais como de private equity (por exemplo, o Banco Pátria investindo na Dasa), de venture capital (por exemplo, Votorantim N ovos N egócios investindo na Alellyx) ou imobiliário (por exemplo, a Prosperitas investindo em projetos imobiliários).

Com os recursos captados ou comprometidos pelos investidores, as empresas gestoras procuram (ou são procuradas por) empreendedores ou empresas já constituídas para então nelas investir. 0 importante nessa etapa é queo empreendedor tenhaum plano de

\section{Tabela - Investidores de PENC.}

\section{INVESTIDOS DE PE/VC}

Distribuição do capital comprometido ao final de 2004 segundo a classe de investidor. Valores reportados em Reais foram convertidos em Dolares usando a cotação média anual, tal como publicado pelo Banco Mundial. Número de veículos refere-se ao número de veículos que possui pelo menos um investidor na categoria. Instituições oficiais internacionais incluem instituições multilaterais e instituições governamentais estrangeiras. Outros incluem classes de investidores com comprometimento agregado inferior a US $\$ 60$ mi: bancos nacionais, empresas privadas nacionais, organizações gestoras de PE/VC nacionais, fundos de investimento nacionais, ONGs e holdings.

\begin{tabular}{|l|c|c|c|}
\hline \multicolumn{1}{|c|}{ CLASSE } & $\begin{array}{c}\text { NÚMERO DE } \\
\text { VEÍCULOS }\end{array}$ & $\begin{array}{c}\text { COMPROMETIMENTOS } \\
\text { (US\$ BILHÕES) }\end{array}$ & $\begin{array}{c}\text { PORCENTAGEM } \\
\text { VÁLIDA }\end{array}$ \\
\hline Investidores institucionais & 39 & 0,96 & 22,4 \\
\hline Organizações mãe & 23 & 0,61 & 14,2 \\
\hline Pessoas físicas externas a organização & 33 & 0,41 & 9,6 \\
\hline Trusts e endowments & 7 & 0,35 & 8,2 \\
\hline Fundos de Investimento internacionais & 12 & 0,34 & 7,9 \\
\hline Governo e empresas públicas & 27 & 0,31 & 7,2 \\
\hline Organizações internacionais de PE/VC & 8 & 0,28 & 6,5 \\
\hline Bancos internacionais & 15 & 0,26 & 6,1 \\
\hline Empresas privadas internacionais & 14 & 0,23 & 5,4 \\
\hline Sócios da organização gestora & 37 & 0,19 & 4,4 \\
\hline Outros & - & 0,22 & 5,1 \\
\hline Sem informação & - & 1,29 & - \\
\hline Total & - & 5,58 & 100,0 \\
\hline
\end{tabular}

Copyright $\odot 2005$ Censo Brasileiro de PE/VC. Todos os direitos reservados.

Fonte: Primeiro Censo Brasileiro de Private Equity e Venture Capital. 
negócios bem estruturado efundamentado para obter os recursos desejados para seu projeto em andamento.

Uma vez constituída a parceria, que pode ser desde uma participação minoritária no negócio, como a tomada de controle do mesmo, a empresa gestora trabal ha com o empreendedor para o sucesso do projeto. Vale lembrar que essa parceria não é necessariamente tranqüila e pacífica, pois os objetivos do empreendedor e da empresa gestora podem ser bastante diversos. Enquanto um foca excessivamente na sua realização pessoal, 0 outro pode dar prioridade ao retorno financeiro. A boa gestão desses conflitos é um diferencial de al gumas das empresas gestoras de PE/VC.

É também na fase de constituição da parceria que as questões jurídicas e contratuais devem ser analisadas cuidadosamente para reduzir esses conflitos, bem como prejuízos futuros entre as partes envolvidas. Para isso, devem ser definidas, desde questões sobre como a empresa deve ser constituída até as cláusulas que definem o comportamento dos acionistas ou cotistas da empresa, como a de drag-along (mecanismo que força os acionistas minoritários a se juntarem aos majoritários no caso de estes decidirem vender a empresa).

Uma vez resolvidas as questões legais, o próximo passo é investir no empreendedor ou na empresa-alvo e gerenciar, monitorar e agregar valor ao empreendimento para alcançar 0 objetivo traçado pela empresa gestora e que satisfarão os anseios dos seus investidores.

Por fim, depois de atingidos os

Com a queda das taxas de juros, do risco país e a grande necessidade de investimentos em setores como tecnologia, infra-estrutura e imobiliário, o Brasil será alvo preferencial, com a China e a Índia, de recursos financeiros provenientes das empresas gestoras de PE/VC.

objetivos de retorno sobre os investimentos realizados, ou se não há perspectivas futuras de se atingir o retorno esperado, a empresa gestora tratará da saída do investimento do empreendedor, seja por venda da participação, pela abertura de capital em Bolsa de Valores (IPO - Initial Public Offering), pelo repasse das cotas ou ações para os investidores, pela assunção do prejuízo ou até mesmo pela falência ou fechamento da empresa.

Empresas beneficiadas. Algumas empresas brasileiras são bons exemplos de investimentos em venture capital no Brasil. A primeira que gostaríamos de mencionar é a Alellyx. A empresa foi fundada em 2002 por um grupo de cinco biólogos molecularese bioinformatas envolvidos nos grupos de pesquisa que seqüenciaram o genoma da bactéria Xylella fastidiosa (causadora da praga do amarelinho nos cítricos). A Alellyx recebeu os recursos da Votorantim N ovos N egócios, uma empresa gestora de capital de risco pertencente ao Grupo Votorantim e direcionada para investimentos em biotecnologia.

O utro exemplo é a Neovia, fundada em 2001 e pioneira na oferta comercial da tecnologia W IMAX, o novo padrão de transmissões wireless (sem fio) para longas distâncias. A Neovia recebeu recursos da Intel Capital, uma empresa da Intel especializada em realizar investimentos em venture capital. Vale lembrar que a própria Intel é uma empresa que passou de empresa investida de venture capital para empresa gestora de investimentos de venture capital.

Como exemplos de investimentos de private equity em negócios maduros, podemos citar o caso da Totvs, empresa de softwares de gestão empresarial econsultoria que recebeu aportes da Advent International, bem como o caso da Dasa (Diagnósticos da América S.A.), tendo o Banco Pátria como sócio.

\section{Dificuldades e perspectivas.} Uma primeira dificuldade envolvida na indústria de PE/VC é a avaliação de seu desempenho, não só pela falta de informações públicas sobre os investimentos elucratividade das empresas, mas também pela dificuldade de mensuração do desempenho. Um estudo da PriceWaterhouseCoopers, de 2006, mostra que os fundos de PE/VC independentes do Reino Unido obtiveram um retorno de $16,4 \%$ ao ano, no horizonte de 10 anos, contra 
um retorno de 7,9\% ao ano do índice FTSE da Bolsa de Londres para o mesmo período de análise.

Por sua vez, pesquisa realizada nos Estados Unidos mostra situação diferente: Kaplan e Schoar, ao considerarem uma amostra de investimentos no período de 1980 a 1997, concluem que, de forma geral, o retorno médio em PE/VC foi igual ao de uma carteira de ações equivalente ao índice S\& P500. Não obstante, esses mesmos pesquisadores encontraram grande variabilidade nos retornos dos investimentos, indicando possibilidade de ganhos e perdas muito maiores aos investidores.

Todavia, se os retornos obtidos forem ponderados pelo capital comprometido, os fundos de venture capital superam o desempenho do índice S\& P500 no período analisado por

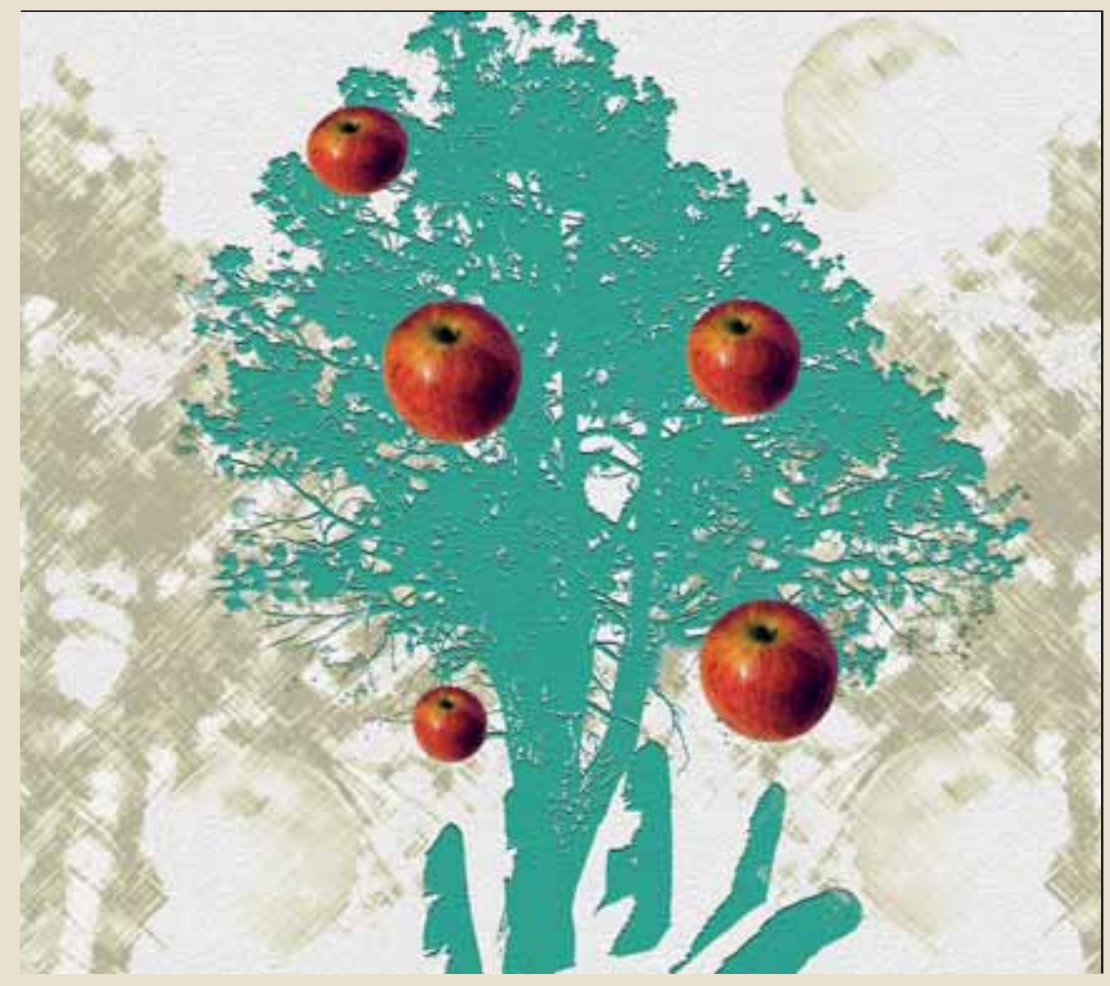

Kaplan e Schoar. Os pesquisadores também identificaram persistência nos retornos obtidos nos investimentos real izad os pelas empresas gestoras de PE/VC.

Uma segunda dificuldade para quem investe em PE/NC é a determinação do valor dos investimentos e projetos investidos, principalmente pela falta de dados públicos sobre as empresas e seus concorrentes, assim como pelo próprio risco do negócio, que pode ser muito alto quando se desenvolve uma nova tecnologia, cuja eficácia não foi comprovada.

A despeito dessas dificuldades, quais são as perspectivas daindústriade PE/VC no Brasil eno mundo? Podemos especular algumas possibilidades. Com a queda das taxas de juros, do risco país eagrandenecessidade deinvestimentos em setores como tecnologia, infra-es-

trutura e imobiliário, o Brasil será alvo preferencial, com a China e a Índia, de recursos financeiros provenientes das empresas gestoras de PE/NC.

A saturação dos mercados europeu e norte-americano levará os investidores dessas regiões a diversificarem e procurarem novas oportunidades nos países emergentes como o Brasil. Além disso, o mercado de capitais brasileiro está se estruturando para facilitar os investimentos e expansão das empresas investidas. Prova disso é a disseminação do Novo Mercado da Bovespa, que espal ha as boas práticas de governança corporativa; a Lei de Falências, que viabiliza a reestruturação de empresas; e o Bovespa Mais, que reduz os custos e facilita a entrada de empresas de pequeno e médio porte no mercado acionário.

Como uma recomendação final, as empresas nacionais devem aprofundar seu conhecimento dessa indústria e, no caso de contactarem ou serem contactadas por empresas gestoras, as potenciais empresas investidas ou empreendedores devem ponderar com cuidado se desejam ter mais um sócio no seu negócio e se estão realmente dispostas a efetuar mudanças, que podem envolver sua estrutura organizacional e de governança e também sua missão e visão do próprio negócio.

Ricardo Ratner Rochman

Doutor em Administração Contábil e Financeira pela FGV-EAESP

Prof. do Departamento de Contabilidade, Finanças e Controle da FGV-EAESP E-mail: Ricardo.Rochman@fgv.br 